\title{
A review of the literature on sexual and reproductive health of African migrant and refugee children
}

Stephen Owusu Kwankye ${ }^{1 *}\left(\mathbb{0}\right.$, Solina Richter ${ }^{2}$, Philomina Okeke-Ihejirika² ${ }^{2}$ Hayat Gomma ${ }^{3}$, Pamela Obegu ${ }^{4}$ and Bukola Salami

\begin{abstract}
Background: Migration and involuntary displacement of children and young people have recently become common features of many African countries due to widespread poverty, rapid urbanization, joblessness, and instability that motivate them to seek livelihoods away from their places of origin. With limited education and skills, children become vulnerable socioeconomically, thereby exposing themselves to sexual and reproductive health (SRH) risks.

Methods: Against this background, the authors undertook a scoping review of the existing literature between January and June 2019 to highlight current knowledge on SRH of African migrant and refugee children. Twenty-two studies that met the inclusion criteria were reviewed.

Results: The results identified overcrowding and sexual exploitation of children within refugee camps where reproductive health services are often limited and underutilized. They also reveal language barriers as key obstacles towards young migrants' access to SRH information and services because local languages used to deliver these services are alien to the migrants. Further, cultural practices like genital cutting, which survived migration could have serious reproductive health implications for young migrants. A major gap identified is about SRH risk factors of unaccompanied migrant minors, which have received limited study, and calls for more quantitative and qualitative SRH studies on unaccompanied child migrants. Studies should also focus on the different dimensions of SRH challenges among child migrants differentiated by gender, documented or undocumented, within or across national borders, and within or outside refugee camps to properly inform and situate policies, keeping in mind the economic motive and spatial displacement of children as major considerations.
\end{abstract}

Conclusion: The conditions that necessitate economic-driven migration of children will continue to exist in subSaharan Africa. This will provide fertile grounds for child migration to continue to thrive, with diverse sexual and reproductive health risks among the child migrants. There is need for further quantitative and qualitative research on child migrants'sexual and reproductive health experiences paying special attention to their differentiation by gender, documented or undocumented, within or across national borders and within or outside refugee camps.

\footnotetext{
*Correspondence: skwankye@ug.edu.gh

1 Present Address: Regional Institute for Population Studies, University of Ghana, Legon, P. O Box LG 96, Accra, Ghana

Full list of author information is available at the end of the article
}

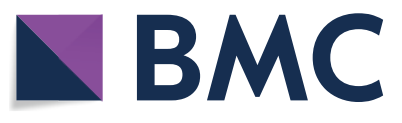

(c) The Author(s) 2021. Open Access This article is licensed under a Creative Commons Attribution 4.0 International License, which permits use, sharing, adaptation, distribution and reproduction in any medium or format, as long as you give appropriate credit to the original author(s) and the source, provide a link to the Creative Commons licence, and indicate if changes were made. The images or other third party material in this article are included in the article's Creative Commons licence, unless indicated otherwise in a credit line to the material. If material is not included in the article's Creative Commons licence and your intended use is not permitted by statutory regulation or exceeds the permitted use, you will need to obtain permission directly from the copyright holder. To view a copy of this licence, visit http://creativecommons.org/licenses/by/4.0/. The Creative Commons Public Domain Dedication waiver (http://creativeco mmons.org/publicdomain/zero/1.0/) applies to the data made available in this article, unless otherwise stated in a credit line to the data. 


\section{Plain language summary}

Child migration is increasingly becoming a common feature of many African countries as children migrate within and away from their countries of origin in search of better livelihoods due to widespread poverty, instability and rapid urbanisation. Many of the migrating children have little or no education and limited employable skills, thereby exposing themselves to sexual and reproductive health $(\mathrm{SRH})$ risks. This paper is a scoping review of existing literature from 2000 to 2019 to document relevant findings on SRH of African migrant and refugee children.

The review identified migrant children within refugee camps to experience overcrowding and sexual exploitation amidst limited and underutilized reproductive health services. Language barriers are also key obstacles against young migrants' access to SRH information and services as these services are delivered in local languages unfamiliar to them. Child migrants continue to suffer from cultural practices including genital cutting with serious reproductive health implications. SRH risk factors of unaccompanied migrant minors remain as a gap in the review and, therefore, more $\mathrm{SRH}$ studies on unaccompanied child migrants are needed. Attention should also be paid to the different dimensions of SRH challenges among child migrants to reflect gender differences, whether documented or undocumented, within or across national borders, and within or outside refugee camps for better understanding.

In conclusion, child migration in Africa will continue to be economic-driven and will expose the actors to diverse sexual and reproductive health risks. Further in-depth quantitative and qualitative research is required to inform relevant policies on child migrants'SRH.

Keywords: Child migration, Sexual health, Reproductive health, African migrant, Refugee children

\section{Background}

Africa is in a demographic transition that is ushering into many countries a rapidly growing youthful population. At the same time, the economies of many of these countries are wrestling with instability, unemployment, and a large informal sector characterized by low and unsustainable incomes. Thus, many sub-Saharan African youth are growing up in an environment of widespread poverty, poor employment prospects, rapid urbanization, limited educational opportunities, and rapid socio-cultural transformations characterized by weakening social controls and the breakdown of traditional norms [1]. This situation has engendered the quest for many young people, especially those with little or no education, to embark on cross-border or within-border migration. These have exposed many children and young people in the region to sexual and reproductive health challenges with serious implications for their health and general well-being.

Since 1994, following the holding of the International Conference on Population and Development (ICPD), there has been a paradigm shift in the conceptualization of sexual and reproductive health, especially among young people. The ICPD conceived reproductive health as a matter of human rights, meaning that people can have a satisfying and safe sex life and that they have the capability to reproduce and the freedom to decide if, when, and how often to do so [2]. Notwithstanding this declaration, the policy and socio-cultural environment in many African settings does not appear to be supportive of the operationalization of this new understanding in several countries in sub-Saharan Africa.
The exposure to sexual and reproductive health risks and vulnerabilities is higher among child and unmarried female adolescent migrants. According to $\mathrm{He}$ et al. [3], for example, the unmarried female migrant is one of the most vulnerable groups recorded in their study. Anecdotal reports suggest that in response to a high level of poverty, unemployment, and low education, some adolescents frequently embark on rural-urban migration within their countries and others engage in cross-border movements, which could fuel their exposure to sexual and reproductive health risks and challenges among them. According to Save the Children [4], boys and girls in transition are seeking to venture into new environments where the social and economic dynamics are not well understood by them, neither are they prepared to navigate, thereby exposing them to vulnerable situations of violence, exploitation and limited access to opportunities. As earlier indicated, this is especially the case among unmarried adolescent females since many of them are unable to negotiate safe and protected sex while unaccompanied away from home.

While some studies have been conducted in countries in Africa to examine the sexual and reproductive health of adolescents and young people, there is no comprehensive compilation of the issues on the sexual and reproductive health vulnerabilities of migrant children that highlights the critical knowledge gaps for further investigation. Against this backdrop, this paper's main objective is to undertake a comprehensive scoping review to document the various dimensions of research 
that have been undertaken in this important area to inform further relevant studies based on the gaps it will reveal.

\section{Methods}

We used a scoping review methodology that consists of five stages [5]. In the first stage of the scoping review, we identified research questions suitable for a scoping review. Our scoping review was guided by the following research questions:

i What is known from the existing literature on the sexual and reproductive health (SRH) of African migrant and refugee children?

ii What is the scope, range, and nature of the evidence on the sexual health of African migrant and refugee children?

At the second stage of the scoping review, we searched multiple databases including Medline, Embase, Global Health, Psych Info, Cochrane Library, CINAHL, SocIndex, Child Development and Adolescent Studies, Sociological Abstract, and ProQuest Dissertations \& Theses Global. The search was completed by an experienced health science librarian in January 2019. We combined search terms related to child (e.g., child, adolescent, youth, pediatric) with search terms related to migrants (refugee, immigrant, asylum seeker, internally displaced persons, etc.) and search terms related to Africa (including the names of all African countries). The search yielded 12,720 articles. A total of 6,602 articles remained after duplicates were excluded. All articles were then exported to Covidence, an online platform designed for article selection and data extraction of systematic reviews.

From February 2019 to May 2019, we completed the third stage of our scoping review and article selection. Six research assistants were involved in article selection. Each article was reviewed by two research assistants on Covidence, a web-based software that streamlines the scoping review process. Disagreements between research assistants were resolved by consensus. The inclusion criteria were that the article must be focused on the health of African migrant, refugee and/or internally displaced children age 0 to 18 years. We only included first generation migrants (i.e., the children must have migrated). We excluded literature reviews, systematic reviews, and articles focused on the experience of parents (without data on the health of the child). The research assistants met with the last author multiple times to clarify inclusion and exclusion criteria and provide mentorship. The last author also completed frequent quality checks on the research assistants' screening on Covidence. At this stage,
1,674 articles met the inclusion criteria based on the review of titles and abstracts. The large volume of articles necessitated us to further narrow down our search. Two research assistants further applied the following inclusion criteria: articles that focused on the reproductive and sexual health of children age 0 to 18 years in sub-Saharan Africa and published between 2000 and 2019. We excluded epidemiological studies where African migrants were only a small variable of a bigger study. For studies where data on children's health were mixed with adults' health or where data on Africans were mixed with non-Africans, we only included these studies if the data were disaggregated in the report (so as to enable us to analyze the data on African children's health only). In total, 22 articles met our inclusion criteria and are included in this review.

The fourth stage is data extraction. We extracted the following information from all 22 articles: author name, title, year of publication, research questions or objectives, methodology, theoretical framework, method (sampling, sample size), age of children, data source (parent versus child versus health professional), period of data collection, country of origin or region, destination country or region, summary of findings, and summary of implications (See Appendix Table 1 for some of the information extracted from the articles).

The final stage involved collating, summarizing, and reporting the results. We identified prevailing categories within our data and summarized the articles within those categories.

\section{Results}

The studies that were reviewed highlighted issues relative to Research Question (i) on the SRH of migrant and refugee children from sub-Saharan Africa on five main themes. These were the following: sexual vulnerabilities/exploitation of immigrant children $(n=9), S R H$ education/communication $(\mathrm{n}=4)$, child protection and resettlement services $(n=3)$, the prevalence of genital mutilation $(n=3)$, and adolescent sexual behavior $(n=3)$.

Concerning Research Question (ii), the 22 studies [627] that were included in the review were made up of 13 qualitative, seven quantitative and two mixed methods studies). The sample size ranged from six (6) to 330 in the qualitative studies and from 47 to 2,344 in the quantitative studies. In contrast, the mixed methods studies had a sample size ranging between 53 and 919. Seventeen of the articles reviewed did not specify a theoretical framework, two used a social-ecological framework, one used a Heise model framework, one of them used a youth resilience framework, and another one used an ecological framework to understand violence. The data sources included children (8), parents/caretakers and adolescents 
(8), parents only (4), and health professionals (2). With regard to the country of study, the review documented the following countries: Democratic Republic of Congo and Ethiopia $(\mathrm{n}=1)$, Rwanda $(\mathrm{n}=3)$, England $(\mathrm{n}=2)$, Ethiopia $(\mathrm{n}=2)$, Uganda $(\mathrm{n}=2)$, Nigeria $(\mathrm{n}=2)$ and one study from each of the following countries: United States of America, Switzerland, Uganda and DRC, Canada, Spain, South Africa, Portugal, Sweden, Zimbabwe with another on Africa in general. Participants originally migrated from the following countries: Democratic Republic of Congo, The Gambia, Senegal, Equatorial Guinea, Ghana, Mali, Nigeria, Somalia, Uganda, Eritrea, Ethiopia, Burundi, Kenya, Rwanda, South Africa, Tanzania, Zambia, and Zimbabwe.

\section{Sexual vulnerabilities and exploitation}

The review identified factors that accounted for migrant children's vulnerability to sexual maltreatment and eventual exploitation especially among those who lived in refugee/displacement camps. These factors included overcrowding in camps, insecurity, and the "miserable life" in camp layouts $[9,12]$. It gave rise to more forms of sexual exploitation such as unwanted physical touching, commercial sex, girl trafficking, and rape, occurring more than once among boys and girls. Other vulnerabilities such as economic hardship, inability to pay school fees, or the desire for independence equally accounted for non-refugee campers' involvement in sex work which led to further migration to maximize income [10]. When asked in a study to describe their experience during adolescence, respondents indicated that it was a time of both vulnerability and opportunity during which they developed some survival skills [10]. The high prevalence of sexual violation among African migrant children [8] has negative effects on their sexual and reproductive health. There is, therefore, some evidence from the studies reviewed to suggest situations of vulnerabilities that confront these child migrants as well as opportunities they strive to take advantage of.

\section{Reproductive health education}

Investigations into awareness and open communication about adolescent reproductive health followed as the second most explored theme. Some of the studies showed that it was difficult for parents and guardians of African immigrant children, especially girls, to educate or have open communications about pubertal development [22] mostly due to widespread myths and taboos about sex in this region of the world. This gap in SRH communication alongside the fear of stigma, was also reported in studies that explored the disclosure of the HIV-positive status of immigrant parents to their children [7]. For some immigrants, language barrier hindered, for example, access to HIV preventive practices or options for contraception since health education at health centres was delivered in the local language that was alien to the migrant children [13]. Other parents admitted that their African cultural background does not encourage open discussions about sexual and reproductive health issues with adolescent children. They perceived Americans as being permissive of sexual behaviours, open in discussing sexual behaviours, and not ending conversations about sex initiated by their daughters [6]. Adolescents felt uneasy discussing sexual issues with their parents, leaving their parents and themselves less informed in this regard. Therefore, culture plays a role in the perspectives and practices among the population relative to SRH. Quite clearly, open communication about SRH with immigrant children is an essential part of their SRH development and yet, many of them are denied this opportunity.

\section{Prevalence of genital mutilation}

Circumcision, or the removal of part of the external genitalia, is reported in some of the studies to be prevalent among immigrant children, especially girls. This prevalence is explained to be greatly accounted for by the culture and practices of some African immigrant parents who view it as an obligatory social and traditional norm [17]. According to Vogt et al. [25], an increased prevalence of female genital mutilation is practiced for the same reasons (as a cultural practice) and is further reported to be supported by the immigrants. In situations where children were not yet circumcised, the intention of parents to cut them in the future was strongly expressed [15]. Immigrant male children were also non-therapeutically circumcised by non-medical professionals, usually older women, as a way of sustaining a cultural practice of the places of origin of these immigrants.

\section{Adolescent sexual behaviour}

Puberty marks the beginning of physical changes in adolescents, but the sexual and reproductive preferences are shaped by behaviours that follow. The studies reveal that adolescents recognized the pubertal changes as signs of early adulthood; they also point to cultural patterns that exist that account for inequitable relations between boys and girls [19]. These culturally fostered inequities greatly furthered the practice of early marriage among immigrant female children $[19,21]$. Immigrant children are exposed to their culture from home and to the culture of the host country. The effect of this juxtaposition is seen in their sexual behaviour, which exposes them to both health and reproductive-related risks. 


\section{Child protection and resettlement services}

Immigrant children who lived in refugee and/or displacement camps were open about their journey of resettling while showing gratitude for the chance to start afresh. They generally expressed the importance of social support, social connectedness, and meaningful social relationships, or sometimes the lack thereof, as important in enabling asylum-seeking and refugee groups to resettle or re-integrate in their home countries [24]. While there were mixed reactions about the habitability of the camps, the issue of underutilization of SRH services in the refugee camps was very common. A situation described as the social consequences of reporting or disclosing abuse by utilizing a formal reporting/referral process emerged as adolescents associated their low utilization of such a key SRH service to the fear of retribution, shame, embarrassment, and social rejection [9]. Total protection and provision may be impossible, as acknowledged by service providers [26], owing to the scarcity of resources and loopholes in reproductive health service provision systems within the refugee camps. Adolescent girls seemed to rely on their interpersonal and communal relations as a source of protection [23]. An obligation society has towards children is protection. Unfortunately, this often eludes them, going by the cries of the unheard voices of unaccompanied or accompanied immigrant children who live through the realities, especially the refugees.

\section{Discussion}

The review has presented issues that when carefully examined could aid in addressing the sexual and reproductive health challenges of migrant and refugee children in Africa, especially when viewed from the gaps that were identified regarding SRH communication between immigrant parents and their children [7]. Also important is the issue of refugee camps in Africa, which are characterized by overcrowding, which resulted from the unpreparedness of most host countries to receive displaced persons in times of civil and political destabilization in the countries of origin. Situations of overcrowding often present fertile grounds for the sexual exploitation of children and young girls. In Ghana, for example, young migrant girls who are compelled to sleep in front of stores and shops at market centres and at the city centres tend to be exposed to sexual exploitation including rape [28]. This is especially when boys and girls congregate together at night in open spaces.

Another source of the vulnerability of migrant and refugee children to sexual and reproductive health challenges, which was evident in the review, was the language barrier that undermines their access to SRH services. In many sub-Saharan African countries, adolescents and young people face socio-cultural barriers in their quest to access SRH information and services. A study in Tanzania reported that both community members and service providers hold the view that it is not appropriate for girls age 10-18 years to access sexual and reproductive health services, especially family planning [29]. Accessing SRH services among young people attracts stigma and discrimination in the community where this study was conducted. In a focus group discussion, one adult male was reported to have said, for example, "I do not think it's right for young people to use family planning methods since it will affect their reproductive health system and unable them to get children" [29]. This barrier in accessing SRH services is also underscored by Save the Children [4] in their observation that both adolescent boys and girls face challenges in accessing services in their new locations while in transition and are confronted with limited livelihood opportunities on arrival in their new destination areas outside their home areas of origin.

There are documented perceptions that contraceptives are for adult married people and not for unmarried adolescents and, yet many unmarried adolescents are sexually active. This is supported by a study on health-care providers' attitudes toward the provision of contraceptives for unmarried adolescents in Ibadan, Nigeria [30]. In the Nigerian study, it was reported that $57.5 \%$ of the respondents were of the view that providing contraceptives to unmarried adolescents would promote sexual promiscuity and $42.7 \%$ said unmarried adolescents should not be provided with contraceptives because the Nigerian culture does not support premarital sex [30]. This means that if a large proportion of family planning service providers at the destination communities of child migrants and refugee children hold such beliefs, it could be a big barrier for adolescents who desire to access SRH information and services. This could result in unplanned or unwanted pregnancies or sexually transmitted infections among the sexually active ones that may resort to unprotected sexual activities in the absence of appropriate services that could get them protected against these unwanted reproductive health outcomes.

For the migrant and refugee children at the destination country, the language barrier was noted in some of the studies as a critical issue for accessing reproductive health information as well as services. The persistence of such language barriers may predispose many of them to be alienated and excluded from any window of opportunity in already-unfriendly environments that are insensitive to their need for sexual and reproductive health services.

It was also clear from the review that access to reproductive health services among the migrant and refugee children is hampered by the myths associated with sex in their communities of origin, which do not empower 
young people to seek information and services. It has also been argued that when people migrate, they are exposed to behaviours and norms that tend to be different from those of their place of origin [31]. Thus, it is possible that as the migrant children stay longer in the destination country, they may be influenced by the prevailing sexual behaviour norms in the destination country to negotiate their way out of the myths surrounding sex at the places of origin. As a result, a young migrant's sexual behaviour may not necessarily be shaped by the myths at the country of origin but instead by the degree of freedom they may experience in their sexual and emotional life in addition to the general level of permissiveness in the host society. Language barriers also tend to constitute a greater challenge among newly arriving child migrants compared to other persons who have stayed in the countries of destination for a much longer time. The latter may already have acquainted themselves with the local languages of their host communities and hence, are better able to navigate sexual behaviours that are different from those left behind at the country of origin. It is also important to stress that in many African countries, many borders often separate people of similar cultures and language groups between countries along common borders. As a result, depending on how far the child migrant moves away from the borders separating the origin and destination countries, language may not constitute a barrier since in many instances, the people along either side of the borders may speak the same or similar languages that may be understood by both of them. Therefore, it is not in all cases that language could be a stumbling block in the way of child migrants who seek SRH information and services in the destination country.

Another critical issue that emerged from the review is female genital cutting that was situated within the cultural context. While this is true, in many countries in Africa such as Nigeria female genital cutting has been outlawed and yet continues to be practised, perhaps due to its link to tradition and culture which many societies still hold, even away from their country of origin. For example, according to an article published in the International Business Times, many girls in Nigeria are still subjected to female genital mutilation despite laws banning the practice [32]. This is interesting because there are anecdotal reports in Ghana that point to children who may be forced to migrate to avoid being subjected to genital cutting against their will. However, in situations where societies are displaced and people are forced to relocate by moving to host countries where female genital cutting is not performed, they still practise genital cutting. This is explained by a clear indication that migrant and refugee parents tend to have a strong bond with the socio-cultural belief systems and practices from their countries of origin. It should, however, be noted that in some cases the migration may be just across a border that simply cuts across one ethnic group that straddles two or more countries. In Africa, such situations abound across borders separating different countries. Therefore, the continuation of such cultural practices after migration into another country may not be a strange development since the socio-cultural environment at the destination may not necessarily be different from that at the origin. It is also the case that in many countries in Africa, female genital cutting has been criminalised although it may be practised under cover in some traditional societies. It may, therefore, be an exaggeration of the situation of female genital cutting as reported in some of the studies reviewed among the immigrant children. Caution should be exercised about the evidence of female genital mutilation reported in some of the studies presented in this review.

Again, some of the studies pointed to gender differentiation relative to SRH in terms of the culturally fostered inequalities between boys and girls. Until quite recently, in many sub-Saharan African countries, the girl child was disadvantaged concerning education and so while the boy child often was taken to school, his girl child counterpart was frequently left behind and cut off from schooling especially after post-primary school. Although much of this is changing, there is still some work to be done to bridge the gender disparity gap, which is confirmed by the early marriages some of the migrant girl children experienced as was reported in some of the studies. Thus, the girl child is more exposed to sexual and reproductive health vulnerabilities due to her relatively lower education and little or no possession of employable skills in addition to her inability to negotiate safe sexual activity because of weak economic strength to fend for herself without depending on male sexual partners, in many instances.

\section{Gaps}

While migration and displacement of children from subSaharan Africa are the result of several reasons that range from economic hardship to the desire to be independent $[10,16]$, there is still a need to conduct studies on SRH risk factors of unaccompanied minors as this was understudied with only one study focusing on unaccompanied migrant minors [14]. There is also a need to conduct follow-up studies to investigate the association between the exposure of these unaccompanied minors to the risk factors observed and the development of adverse health outcomes. Although 13 out of the 22 studies reviewed were qualitative studies, in comparison to the seven that used quantitative methods, there is a need for more qualitative research that will further elucidate the reproductive and 
sexual health needs and concerns of migrant and refugee children from sub-Saharan Africa beyond surveys and predetermined sets of interview questions.

Perhaps, the conduct of more mixed methods-driven studies could assist in providing more insight into the underlying explanations of sexual and reproductive health vulnerabilities among young migrant children in Africa. The qualitative aspects of such studies could lend further in-depth explanation for some of the quantitative analytical results. Such studies have the advantage of giving a holistic overview of the situation in different country settings either as destination or origin of child migrants.

Most of the studies reviewed do not distinguish between the situations of accompanied and unaccompanied children and their exposure to sexual and reproductive health risks after their migration. Most of them lump them together and it is, therefore, not possible to discuss possible differences between the two groups of migrant children. This gap in the review requires targeted research to aid our enhanced understanding of the possible differences between the two groups of child migrants.

\section{Conclusion}

In most of Africa, child migration is mainly driven by economic motives. There is always an element of economic motive that underlies child migration decision making. On the other hand, some are forced to migrate due to internal displacement circumstances resulting from natural disasters and civil and political instability. As long as the conditions that necessitate economic-driven migration of children continue to exist in sub-Saharan Africa, child migration will continue to thrive with its attendant exposure of the actors to sexual and reproductive health risks. While non-migrant children and adolescents at the country of origin do experience similar sexual and reproductive health challenges just like their migrant counterparts, the challenges are higher among the migrants.

However, migrant social networks provide safety nets to support many of the migrant children to address their reproductive health vulnerabilities at their destination countries or places of residence through the adoption of certain coping strategies. At the refugee camps, the establishment of the camps should factor sexual and reproductive health information and service provision right from the inception of the camps to overcome the underutilization of these services. More quantitative and qualitative studies could provide a more in-depth understanding of the different dimensions of sexual and reproductive health challenges among child migrants differentiated by gender, documented or undocumented, within or across national borders and within or outside refugee camps. This is important to inform different policy decisions targeted at the different actors and situations involved in child migration, particularly within sub-Saharan Africa where the economic motive for the migration of children is always a major consideration.

\section{Appendix}

See Table 1. 


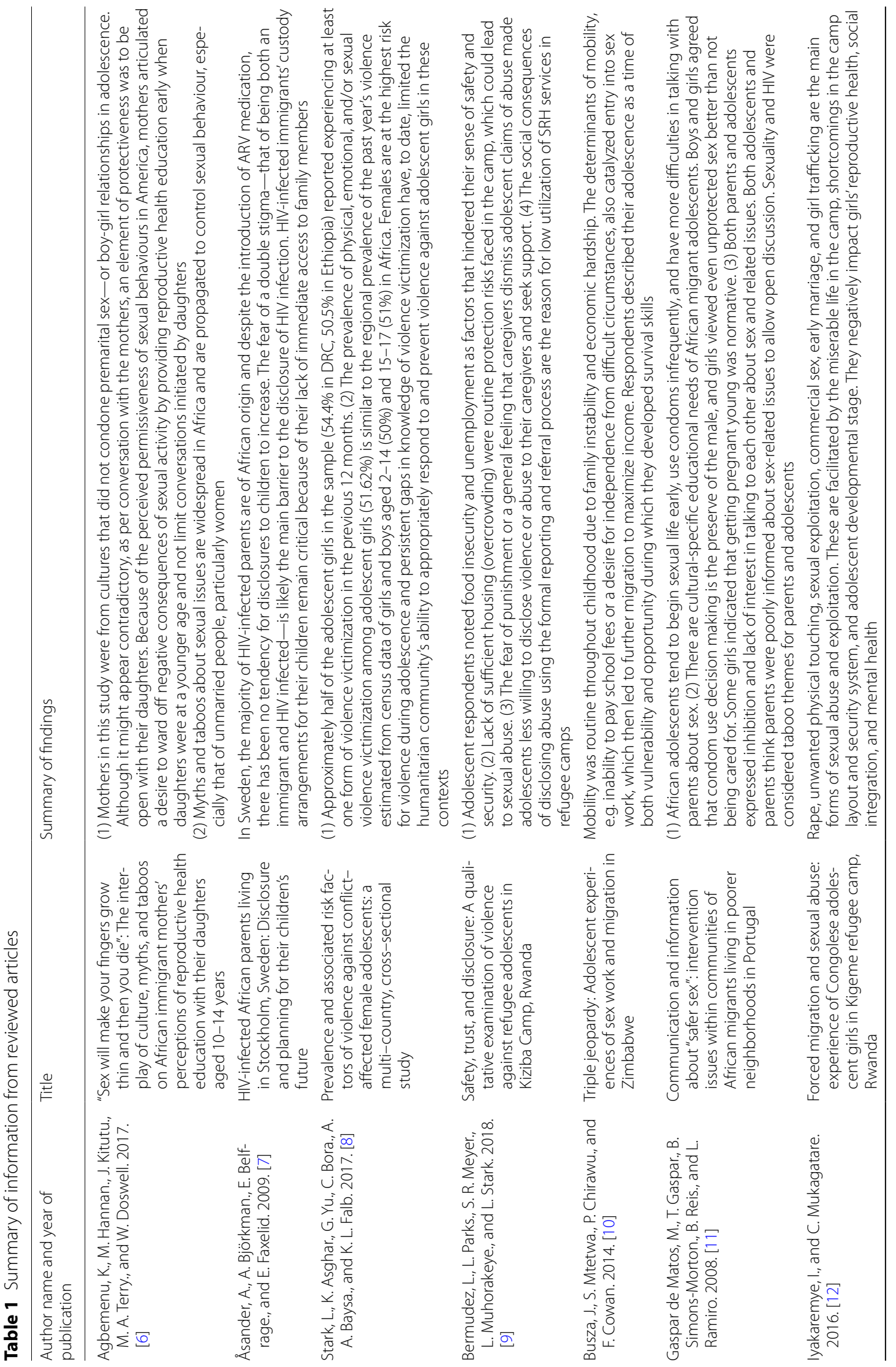




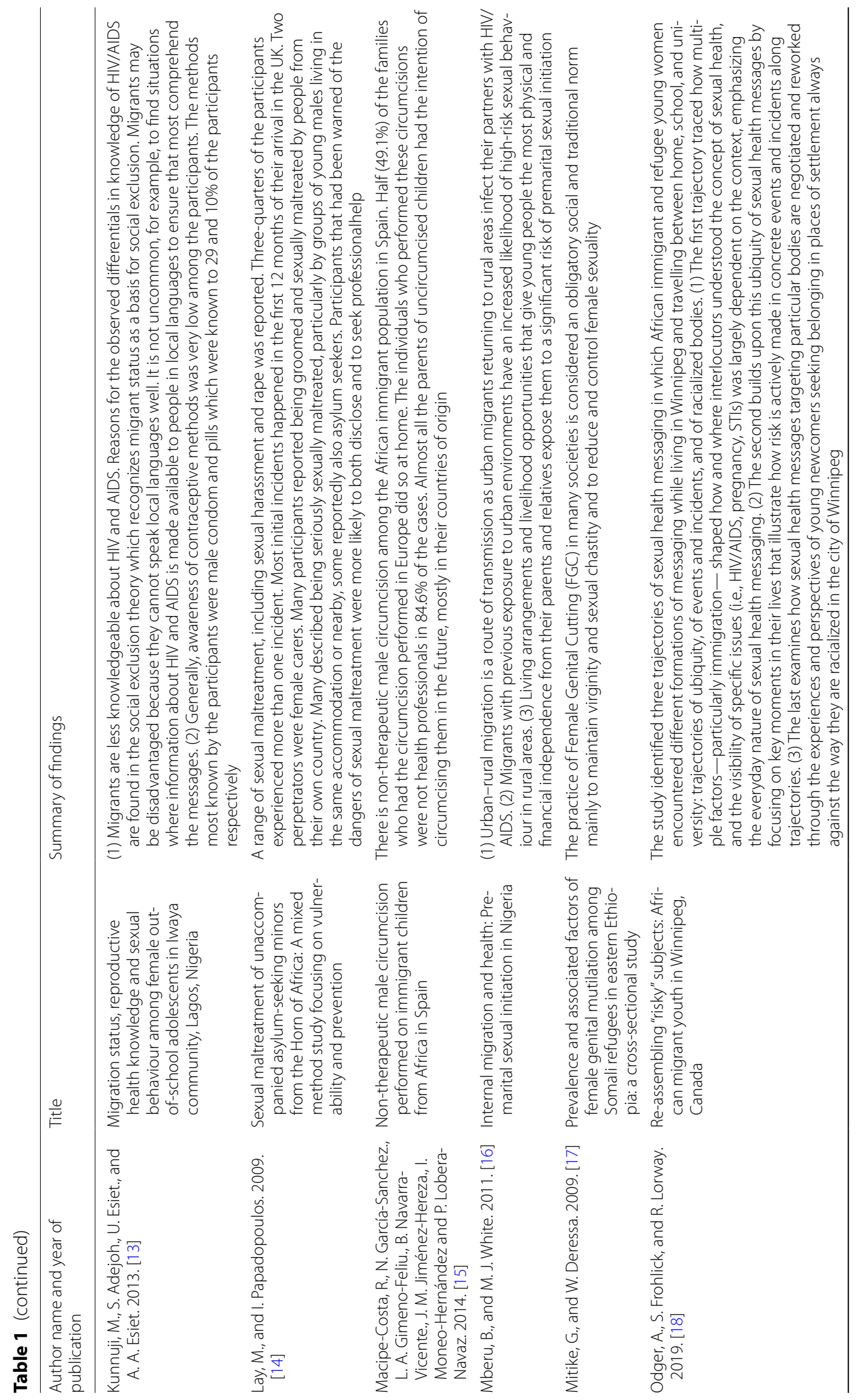



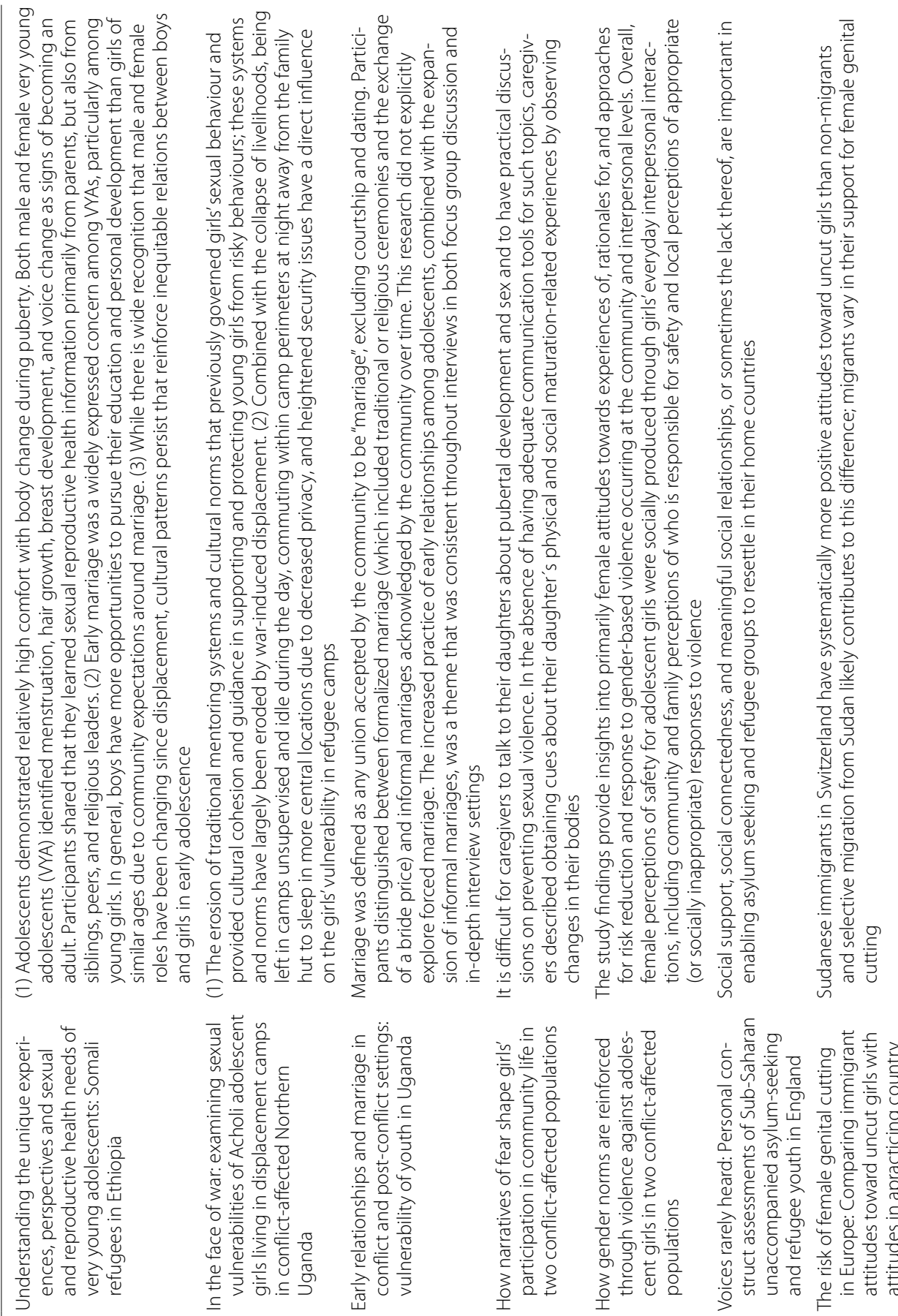

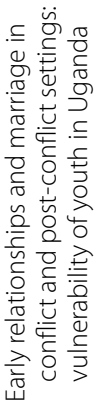

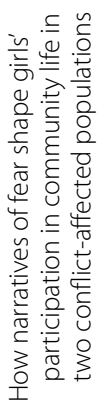

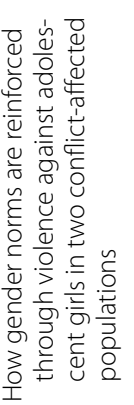

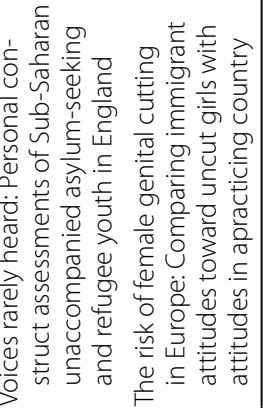
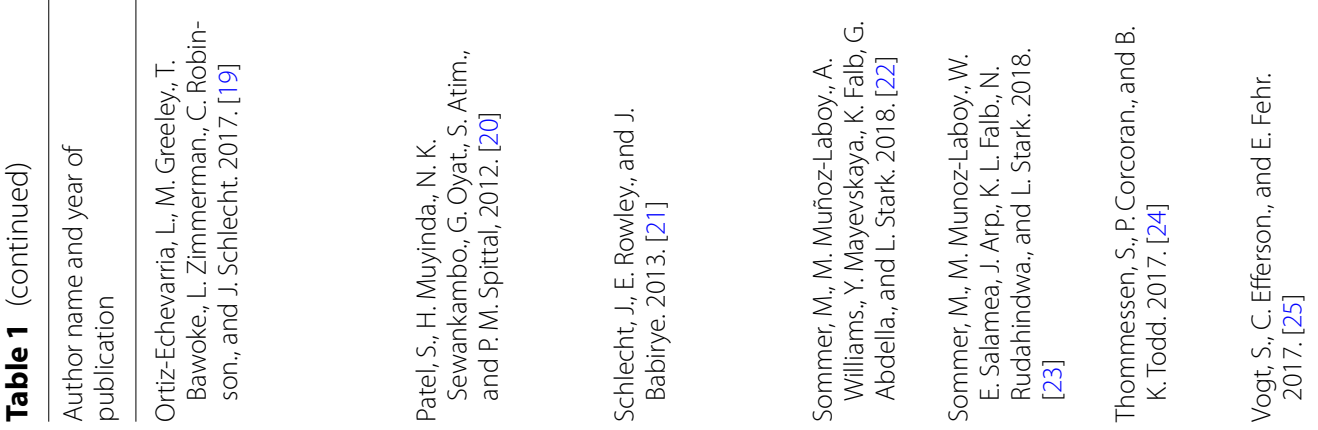


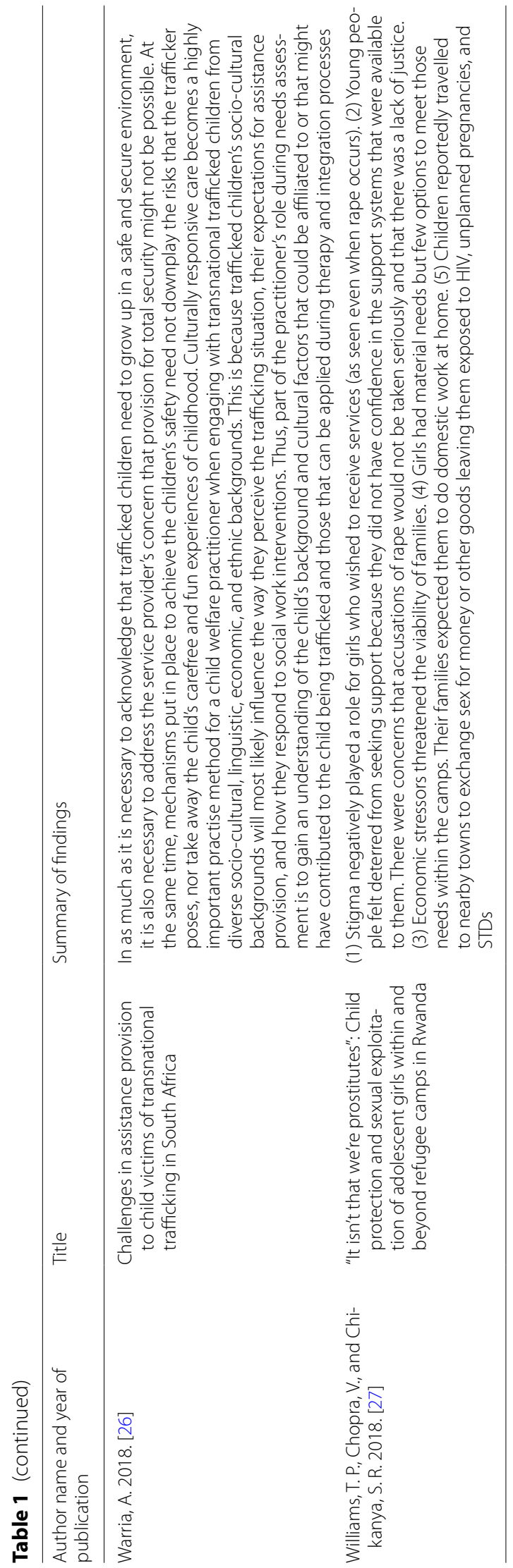




\section{Acknowledgements}

We acknowledge the funding under the Worldwide Universities Network (WUN) that enabled us to form the WUN on Child Migrants and Refugee Studies. We also acknowledge the support provided by research assistants at the University of Alberta during the literature search.

\section{Authors' contributions \\ All the authors have contributed in diverse ways to bring this paper to its present status. These are presented as follows: \\ 1. SOK wrote the abstract, introduction, discussion and formatting of the paper as well as serving as the corresponding author; \\ 2. SR provided multiple review and edit of the paper; \\ 3. PO wrote the results section and first draft of the table; \\ 4. BS wrote the methodology and provided multiple review and feedback; \\ 5. HG and PO-I provided multiple review of the paper and feedback. \\ All authors read and approved the final manuscript.}

\section{Authors' information}

Authors' institutional affiliation has already been indicated against them on the title page as footnote.

\section{Availability of data and materials}

There were no primary data collected for the paper. However, details of the review have been summarised in a table and included in the paper.

\section{Declarations}

\section{Ethics approval and consent to participate}

The paper is a scoping review and so no human subjects were directly interacted with for data collection. Therefore, no ethical approval was required.

\section{Consent for publication}

The publication of this paper is part of the funding agreement on "African Child migration in circumstances of vulnerabilities" and vulnerability". In addition, all the authors have given their consent to the publication as key contributors.

\section{Competing interests}

The authors for this paper have no competing interests.

\section{Author details}

${ }^{1}$ Present Address: Regional Institute for Population Studies, University of Ghana, Legon, P. O Box LG 96, Accra, Ghana. ${ }^{2}$ University of Alberta, Edmonton, Canada. ${ }^{3}$ Ahmadu Bello University, Zaria, Nigeria. ${ }^{4}$ Heartwood House and Volunteers at Oxfam, Ottawa, Canada.

Received: 27 November 2020 Accepted: 12 April 2021

Published online: 17 April 2021

\section{References}

1. Blum R, Bastos FL, Kabiru CW, Le LC. Adolescent health in the 21st century. Lancet. 2012. https://doi.org/10.1016/S0140-6736(12)60407-3.

2. UNFPA. Programme of Action Adopted at the International Conference on Population and Development, Cairo, 5-13 September 1994. United Nations Population Fund, New York (2004). https://www.unfpa.org/sites/ default/files/event-pdf/PoA_en.pdf. Accessed 12 Oct 2020.

3. He D, Zhou Y, Ji N, Wu S, Wang Z, Decat P, Moyer E, Minkauskienne M, Pang C, Cheng Y. Study on sexual and reproductive health behaviors of unmarried female migrants in China. J Obstet Gynaecol Res. 2012. https://doi.org/10.1111/j.1447-0756.2011.01753.x.

4. Save the Children. Adolescents in transition in the Horn of Africa. (2018) https://resourcecentre.savethechildren.net/node/13375/pdf/adole scents_in_transition_in_the_horn_of_africa.pdf. Accessed 12 Oct 2020.

5. Arksey H, O'Malley L. Scoping studies: towards a methodological framework. Int J Soc Res Methodol. 2005. https://doi.org/10.1080/1364557032 000119616

6. Agbemenu K, Hannan M, Kitutu J, Terry AM, Doswell W. Sex will make your fingers grow thin and then you die: the interplay of culture, myths, and taboos on african immigrant mothers' perceptions of reproductive health education with their daughters aged 10-14 years. J Immigr Minor Health. 2017. https://doi.org/10.1007/s10903-017-0675-4.

7. Åsander A, Björkman A, Belfrage E, Faxelid E. HIV-infected African parents living in Stockholm, Sweden: disclosure and planning for their children's future. Health Soc Work. 2009. https://doi.org/10.1093/hsw/34.2.107.

8. Stark L, Asghar K, Yu G, Bora C, Baysa AA, Falb KL. Prevalence and associated risk factors of violence against conflict-affected female adolescents: a multi-country, cross-sectional study. J Glob Health. 2017. https://doi. org/10.7189/jogh.07.010416.

9. Bermudez L, Parks L, Meyer SR, Muhorakeye L, Stark L. Safety, trust, and disclosure: a qualitative examination of violence against refugee adolescents in Kiziba Camp, Rwanda. Soc Sci \& Med. 2018. https://doi.org/10. 1016/j.socscimed.2018.01.018.

10. Busza J, Mtetwa S, Chirawu P, Cowan F. Triple jeopardy: adolescent experiences of sex work and migration in Zimbabwe. Health Place. 2014. https://doi.org/10.1016/j.healthplace.2014.04.002.

11. de Gaspar Matos M, Gaspar T, Simons-Morton B, Reis M, Ramiro L. Communication and information about safer sex: intervention issues within communities of African migrants living in poorer neighborhoods in Portugal. J Poverty. 2008. https://doi.org/10.1080/10875540802198628.

12. Iyakaremye I, Mukagatare C. Forced migration and sexual abuse: experience of Congolese adolescent girls in Kigeme refugee camp, Rwanda. Health Psychology Report. 2016. https://doi.org/10.5114/hpr.2016.59590.

13. Kunnuji MO, Adejoh S, Esiet U, Esiet A. Migration status, reproductive health knowledge and sexual behaviour among female out-of-school adolescents in Iwaya community, Lagos. Nigeria African Journal of AIDS Research. 2013. https://doi.org/10.2989/16085906.2013.864985.

14. Lay M, Papadopoulos I. Sexual maltreatment of unaccompanied asylumseeking minors from the Horn of Africa: a mixed method study focusing on vulnerability and prevention. Child Abuse Negl. 2009. https://doi.org/ 10.1016/j.chiabu.2009.05.003.

15. Macipe-Costa RM, García-Sanchez N, Gimeno-Feliu LA, NavarraVicente B, Jiménez-Hereza JM, Moneo-Hernández I, Lobera-Navaz P. Non-therapeutic male circumcision performed on immigrant children from Africa in Spain. Int J Public Health. 2014. https://doi.org/10.1007/ s00038-013-0522-X.

16. Mberu B, White MJ. Internal migration and health: premarital sexual initiation in Nigeria. Soc Sci Med. 2011. https://doi.org/10.1016/j.socscimed. 2011.02.019.

17. Mitike G, Deressa W. Prevalence and associated factors of female genital mutilation among Somali refugees in eastern Ethiopia: a cross-sectional study. BMC Public Health. 2009. https://doi.org/10.1186/1471-2458-9-264.

18. Odger A, Frohlick S, Lorway R. Re-assembling risky subjects: african migrant youth in winnipeg Canada. Med Anthropol. 2019. https://doi. org/10.1080/01459740.2018.1551390.

19. Ortiz-Echevarria L, Greeley M, Bawoke T, Zimmerman L, Robinson C, Schlecht J. Understanding the unique experiences, perspectives and sexual and reproductive health needs of very young adolescents: Somali refugees in Ethiopia. Confl Heal. 2017. https://doi.org/10.1186/ s13031-017-0129.

20. Patel S, Muyinda H, Sewankambo NK, Oyat G, Atim S, Spittal PM. In the face of war: examining sexual vulnerabilities of Acholi adolescent girls living in displacement camps in conflict-affected Northern Uganda. BMC Int Health Hum Rights. 2012;12:38.

21. Schlecht J, Rowley E, Babirye J. Early relationships and marriage in conflict and post-conflict settings: vulnerability of youth in Uganda. Reprod Health Matters. 2013. https://doi.org/10.1016/S0968-8080(13)41710-X.

22. Sommer M, Munoz-Laboy M, Salamea WE, Arp J, Falb KL, Rudahindwa $\mathrm{N}$, Stark L. How narratives of fear shape girls' participation in community life in two conflict-affected populations. Violence Against Women. 2018;24:565-85.

23. Sommer M, Muñoz-Laboy M, Williams A, Mayevskaya Y, Falb K, Abdella $\mathrm{G}$, Stark L. How gender norms are reinforced through violence against adolescent girls in two conflict-affected populations. Child Abuse Negl. 2018. https://doi.org/10.1016/j.chiabu.2018.02.002.

24. Thommessen S, Corcoran P, Todd BK. Voices rarely heard: personal construct assessments of Sub-Saharan unaccompanied asylum-seeking and refugee youth in England. Child Youth Serv Rev. 2017. https://doi.org/10. 1016/j.childyouth.2017.08.017. 
25. Vogt S, Efferson C, Fehr E. The risk of female genital cutting in Europe: comparing immigrant attitudes toward uncut girls with attitudes in a practicing country. SSM-Population Health. 2017. https://doi.org/10. 1016/j.ssmph.2017.02.002.

26. Warria A. Challenges in assistance provision to child victims of transnational trafficking in South Africa. Eur J Soc Work. 2018. https://doi.org/10 1080/13691457.2017.1320534.

27. Williams T, Chopra V, Chikanya SR. It isn't that we're prostitutes: child protection and sexual exploitation of adolescent girls within and beyond refugee camps in Rwanda. Child Abuse Negl. 2018. https://doi.org/10. 1016/j.chiabu.2018.09.015

28. Anarfi JK, Kwankye SO (eds). Independent migration of children in Ghana. Institute of Statistical, Social and Economic Research (ISSER), University of Ghana, Legon, Accra: Sundel Services; 2009.

29. Mbeba R, Mkuye MS, Mkuwa SB. Barriers to sexual reproductive health services and rights among young people in Mtwara district, Tanzania: a qualitative study. Pan Afr Med J. 2012;13(Suppl 1):1-21.
30. Ahanonu LE. Attitudes of healthcare providers towards providing contraceptives for unmarried adolescents in Ibadan, Nigeria. J Family Reprod Health. 2014;8:33-40.

31. Coast E. Sexual behaviour and perceptions of risk: male rural-urban migrants in Tanzania. (n.d). http://www.tzonline.org/pdf/sexualbehaviour andperceptionsofrisk.pdf. Accessed 16 Jan 2020.

32. Laccina L, Palumbo D. Female genital mutilation in Nigeria mostly practised in Christian and traditional communities. https://www.ibtimes.co. uk/fgm-nigeria-mostly-practised-girls-christian-traditional-communities1585776. Accessed $16 \operatorname{Jan} 2020$.

\section{Publisher's Note}

Springer Nature remains neutral with regard to jurisdictional claims in published maps and institutional affiliations.
Ready to submit your research? Choose BMC and benefit from:

- fast, convenient online submission

- thorough peer review by experienced researchers in your field

- rapid publication on acceptance

- support for research data, including large and complex data types

- gold Open Access which fosters wider collaboration and increased citations

- maximum visibility for your research: over $100 \mathrm{M}$ website views per year

At BMC, research is always in progress.

Learn more biomedcentral.com/submissions 